EVIDENCE BASED PUBLIC HEALTH POLICY AND PRACTICE

\title{
Health impact assessment for the sustainable futures of Salford
}

\author{
Calbert H Douglas, Alan Higgins, Chris Dabbs, Mick Walbank
}

J Epidemiol Community Health 2004;58:642-648. doi: 10.1136/jech.2003.010397

See end of article for authors' affiliations

Correspondence to: Dr C H Douglas, The Crescent, School of Environment and Life Sciences, University of Salford, Salford M5 4WT, UK; c.h.douglas@salford. ac.uk

Accepted for publication 22 October 2003

\begin{abstract}
Background: The Salford Health Investment for Tomorrow and the Local Improvement Finance Trust proposals for the comprehensive redevelopment of Salford Royal Hospital and the provision of four integrated primary health and social centres in the City of Salford are a response to the challenge of the NHS Plan to modernise delivery and service provision. The scale of the proposed developments will have a major effect on the quality of life in Salford. This health impact assessment was undertaken to determine how these proposals could be amended to ensure that the impacts are optimised so that potential benefits to Salford's communities are realised to maximise their health and wellbeing.

Method: This involved a comprehensive prospective health impact assessment and a series of interviews with key stakeholders, community organisations, and local people to identify and prioritise potential positive and negative impacts of the proposals.

Results and conclusions: The assessment pointed to a wide range of positive and negative impacts that provided the basis of a set of recommendations, which were linked directly to the themes of the Salford Community Plan. These related to setting employment, education, and training opportunities to maximise health and wellbeing and improve quality of life for all communities in Salford within the framework of the plan. In presenting the findings of the health impact assessment and discussing the recommendations, the paper presents a unique approach in health impact assessment reporting by offering perspectives from the assessor and the project's steering group.
\end{abstract}

importance to its commissioning, scoping and in drawing up implementation and monitoring strategies with the developer. Three steering group members represented public and community health in Salford and local people and were instrumental in commissioning the HIA. In preparing this paper, the assessor requested their independent views on the HIA, including its outcomes and potentials.

\section{THE HIA COMMISSIONING PROCESS}

The HIA was commissioned after the lobbying for an assessment by the Salford Community Health Council (CHC), the director of public health in Salford, and a number of concerned locals. Following the procedural and methodological approach suggested by the Liverpool Public Health Observatory, a steering group was formed to recruit an HIA assessor to advise the process accordingly. ${ }^{4}$ The remit of the HIA assessor was to identify, evaluate, and prioritise the project's impacts, to determine how it could contribute to health and wellbeing, personal development, and reduction of health inequalities in Salford. The prospective nature of the HIA offered the opportunity to influence the project's proposals at the planning stages and enabled the "whole systems" approach to be applied in the health planning process within Salford.

\section{HEALTH STATUS AND DETERMINANTS OF HEALTH}

HIA assessors base their approach on a model that has psychological, social, economic, cultural, and biological factors as its premise in terms of the determinants of health. ${ }^{4-6}$ This arises from a definition of health that rests upon notions of health and wellbeing. Health status thus

Abbreviations: HIA, health impact assessment; SHIFT, Salford Health Investment for Tomorrow; LIFT, Local Improvement Finance Trust; PCT, primary care trust and building four integrated PCT health and social care centres across Salford. An HIA steering group is of central 
relates to economic and social conditions across community groups in an area. $^{78}$ These studies suggest that specific influences within the categories of such non-medical health determinants; for example, biological factors, family circumstances and lifestyle behaviours, social and cultural environments, physical environments, public services and policies can significantly affect the wellbeing of people within a local community as they influence people's health status. ${ }^{9-11}$ This means that HIA studies should include assessments of those factors that are known health status determinants. Thus, the sustainable future of a community requires improvements in and maintenance of its health status along with future economic opportunities.

\section{PROFILE OF THE CITY OF SALFORD}

The City of Salford lies central to the Greater Manchester conurbation and has a population of $230500 .{ }^{12}$ Salford is the fourth most deprived local authority area in north west England and the 28th nationally. In the period between 1965 and 1991 the city lost 49000 jobs, 32\% of its employment base. ${ }^{13}$ Some service sector expansion occurred during the 1990s but this did not compensate for the decline in the city's traditional economic base. Many wards of Salford are among the worst affected by deprivation and ill health in the country and reflected the relatively low health status within the city. The continued relatively high unemployment of the 1990s across Salford has compounded the social malaise. Risk taking behaviour, such as crime, violence, vandalism, and substance use, affects personal and family circumstances and lifestyle and social environment, two important categories of influences on health. ${ }^{4}$ Crime is comparatively high in Salford and with unemployment is a significant influence on health status in the city.

\section{OUTLINE OF THE PROJECT'S PROPOSALS}

The joint SHIFT and LIFT project put the NHS Plan into practice in transforming local health and social care infrastructure in Salford. The project entails a redesign of services to improve patients' experience, to deliver more accessible, effective, and responsive care and to provide responsive and personalised 24 hour integrated health and social care across the city. The proposals entail two distinct aspects. First is a physical aspect, which relates to the redevelopment of the SRHT, which employs around 3500 people, provides local, regional, and national services and is a major teaching facility, and the provision of four PCT health and social care

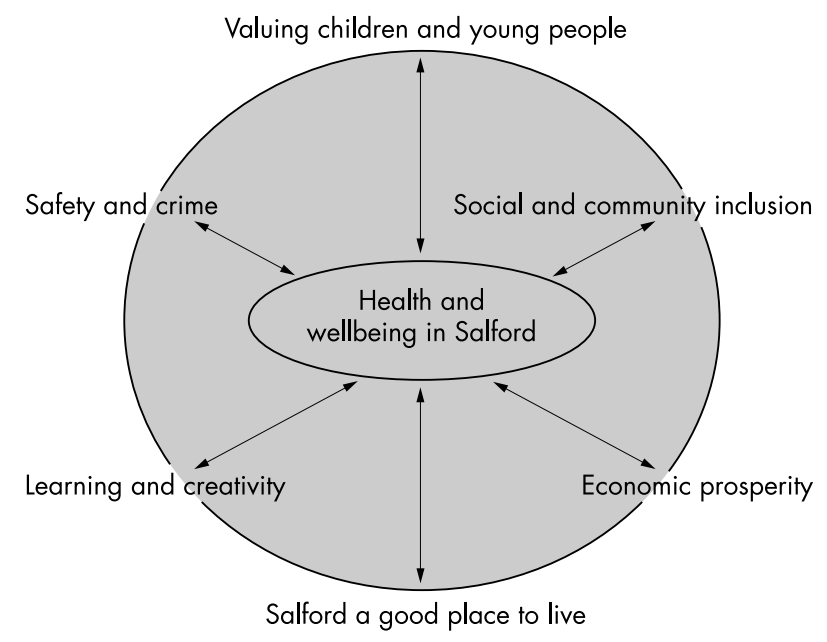

Figure 1 HIA groups linked to the themes of Salford's community plan.

\section{Policy implications}

Policy implications involve the willingness of the Partnership Board in Salford and health authorities across the UK to develop a health agenda that is based around healthy living and wellbeing. The Partnership Board must:

- Promote the shift in thinking and provide the impetus to change by using the project's economic and social regeneration potentials to attain this objective.

- Appreciate and understand the potentials of the project and its role in developing and maintaining the sustainable future of Salford. In so doing, it must use the phases of the project to implement and promote economic prosperity and encourage social and community inclusion within the city.

- Develop the policy of working with the Salford Parnership, local forums, and enterprise units to realise the positive impacts revealed by the assessment and reduce the negative impacts.

- Recognise and promote the need of Salford's communities for wider multi-purpose facilities and use of local healthcare centres. For example, the health and social centres should provide onsite facilities for voluntary services, health promotion activities, leisure, sport and play, community cafes, and green garden areas around them.

- Take up the opportunity to make significant contributions to promoting creativity and learning by developing programmes that link with local schools and colleges. This will be of benefit to Salford's children and young people as it will enhance their self belief and esteem as they become aware of career potentials with the project in its developmental stage and operational years.

centres at locations in Salford. The second aspect is a decentralised service model. This relates to the proposed shift in some healthcare elements from the central SRHT site to the PCT health and social care centres within the city's communities. Both aspects have radical implications for the potential sustainable futures of Salford's communities. The project's proposals follows the "whole systems" approach, which implies that it will take account of the full range of agencies involved and the factors that influence health and wellbeing in Salford.

\section{METHODOLOGY}

The HIA was carried out over a period of four months in which the views of local people and key informants were gathered, evaluated, and prioritised. The scope of the HIA, in terms of the geographical boundaries, time covered by the assessment, and the sources of secondary data by which to determine the health status of the local population, was agreed upon with the HIA steering group. The geographical boundaries were confined to the City of Salford as this was the principal area in which the major impacts would be felt. The assessment covered the period from site clearance up to completion and over the first 10 years of operations. A prospective HIA day was held at the University of Salford, which was attended by 50 delegates, including carers, health managers, and community leaders. Delegates self selected into impact assessment groups under each of six themes of the City of Salford's community plan (fig 1). 
Key informant interviews were conducted with community representatives, professionals, and health agencies across Salford. During the process of carrying out the interviews, some interviewees suggested further informants who could make contributions. Using this snowballing technique, further experts and informants were consulted, which culminated in 25 interviews. Five meetings were held with local groups in communities across Salford. These included discussions with a young mums and toddlers group, a local credit union group, an elderly people's healthy hips and heart group, and two local residents' action groups. Thus qualitative information was collected that related to the views, perceptions, and opinions expressed by experts, key informants, and community group members. Quantitative data on health, demography, economic, unemployment, and social conditions by which to determine the health status of the city were collected from published secondary sources.

\section{HIA findings and ASSESSORS and steering group perspectives HIA findings}

Discussions with the key informants suggested that there would undoubtedly be positive health benefits from the redevelopment and the provision of the new PCT health and social centres, especially those that will be located in the peripheral areas of Salford. These experts considered that positive benefits would flow directly from the planned "whole systems" model of care, the new and improved facilities and the advanced information technology in administrative applications. Positive health outcomes will also flow from the improved access to secondary care, from the reduced waiting times because of the planned numbers of new beds, and from the improvements in clinical and community services both at SRHT and in the new health and social centres. They considered that the new PCT centres will also alleviate distance related illness, reportedly incurred by elderly patients and their families who make long journeys to the central hospital site. Interviews with the community groups identified the need for the project to support their health by helping to develop social and community facilities at the main SRHT site and at the new health and social centres. Many called for SHIFT and LIFT to promote social inclusion and encourage local empowerment. In contrast, the emphasis from health agencies involved in the project was predominantly the modernisation of treatment and delivery services.

The comprehensive assessments in which delegates were arranged under each of the separate themes of the Salford community plan produced 94 separate tables of impacts. ${ }^{2}$ Table 1 to table 6 provide the prioritised set of impacts for each of the main categories of health determinants of biological factors, personal/family circumstances and lifestyle, social environment, physical environment, public services, and public policies. As the set of tables show, the impacts were considered by each of the groups that were set up under the respective themes of the Salford Plan. The tables of impacts suggest that, separate from the direct and immediate clinical health benefits that will come from the new hospital with its modern equipment and facilities, positive health impacts will arise if the project realises its potential as a major job creator at all occupational levels in Salford. The assessment found that negative outcomes are

Table 1 Summary of health impacts in the biological category of health determinants

\begin{tabular}{|c|c|c|}
\hline Category of influence & Positive impacts & $\begin{array}{l}\text { Community plan theme groups } \\
\text { linked to each impact }\end{array}$ \\
\hline $\begin{array}{l}\text { Biological factors: age, gender, } \\
\text { genetic factors }\end{array}$ & $\begin{array}{l}\text { Enhanced quality of life as SHIFT and LIFT is a major job creator for working age } \\
\text { community } \\
\text { - Increased self esteem and wealth creation. The projects provide opportunity for } \\
\text { school leavers } \\
\text { - Increased employment levels and wealth creation as young people are trained and } \\
\text { encouraged to take up healthcare careers } \\
\text { Increased quality of life and general wellbeing as employment opportunities are } \\
\text { targeted for underemployed groups, for example, people with learning difficulties, } \\
\text { mental health problems. } \\
\text { - Longer term community wide educational benefits, if the programme develops } \\
\text { immediate links with schools } \\
\text { - Young people will benefit from SHIFT and LIFT sponsored training programmes } \\
\text { and clear career development path } \\
\text { - Reductions in crime as young people become involved with the SHIFT and LIFT } \\
\text { programmes } \\
\text { The new primary care and social centres will alleviate stress and anxiety related } \\
\text { illness incurred by elderly patients and their families who make long journeys to } \\
\text { the central site. } \\
\text { - Increased social inclusions if the project involves communications with excluded } \\
\text { groups, including people from the gay and lesbian communities } \\
\text { Negative impacts } \\
\text { The elderly fear of crime increases. } \\
\text { Increase in misbehaviour and in juvenile crime. } \\
\text { - Anxiety and stress caused by youth groups around the development. } \\
\text { Increase in mental health problems because of lack of facilities in areas such as } \\
\text { Ordsall and Broughton. } \\
\text { - Minority groups excluded, unequal opportunities; equal opportunity policy has not } \\
\text { worked. } \\
\text { - Health targets are not achieved because of lack of provision of men and women } \\
\text { health clinics and facilities for gays and lesbians. } \\
\text { - Parking and access to facilities are still limited creating problems for those with } \\
\text { impairments or disablements. } \\
\text { - Potential physical injury and stress because of unsocial behaviour or violence to } \\
\text { nurses and women around the centres. } \\
\text { Kids cannot use the new centres for social activities. }\end{array}$ & $\begin{array}{l}E P \\
E P, S F C, L C \\
E P, \text {, LC } \\
E P, S G, S C l \\
\text { VC, EP, LC } \\
\text { VC, EP, LC } \\
\text { SFC, VC } \\
\text { SFC } \\
\text { SFC, SCI } \\
\text { SFC } \\
\text { SFC, VC } \\
\text { SFC, VC } \\
\text { SFC } \\
\text { SFC, SCI } \\
\text { SFC, SCI } \\
\text { SG, SCI,VC } \\
\text { SFC, SG, VC } \\
\text { SCI }\end{array}$ \\
\hline
\end{tabular}

SCl, social and community inclusion group; EP, economic prosperity group; SG, Salford a good place to live; LC, learning and creativity group; SFC, safety and crime group; VC, valuing children and young people. 
Table 2 Summary of health impacts in the personal/family category of health determinants

\begin{tabular}{|c|c|c|}
\hline Category of influence & Positive impacts & $\begin{array}{l}\text { Community plan theme groups } \\
\text { linked to each impact }\end{array}$ \\
\hline $\begin{array}{l}\text { Personal/family circumstances } \\
\text { and lifestyle behaviours, } \\
\text { occupation, education }\end{array}$ & $\begin{array}{l}\text { - Social and community agencies linking with SHIFT and LIFT and all } \\
\text { working together. } \\
\text { - Improved psychological wellbeing in individuals and in families as a result of the } \\
\text { increase in employment } \\
\text { - Decrease in mortality risks and decreased poverty and social disadvantage } \\
\text { - for children and young people in families where parents regain paid employment } \\
\text { - Enhanced quality of life if the full employment potentials are realised during } \\
\text { the phase. } \\
\text { - Targeted education and work experience for young people in health related } \\
\text { - } \text { Imprammes } \\
\text { - diseaved diet for families and young people reduces future risks of heart } \\
\text { Raised expectation from citizens, leading to optimism and improved psychological } \\
\text { wellbeing } \\
\text { Negative impacts } \\
\text { - Increased psychological distress and ill health due to insecurity about } \\
\text { - Temployment prospects. } \\
\text { increorary employment has potentially detrimental psychosocial health effects, } \\
\text { - Increased anxiety, depression, and cardiovascular problems. } \\
\text { - Lack of education to combat unsocial behaviour } \\
\text { - The required skills are not available in the community so jobs go to people from } \\
\text { outside Salford. } \\
\text { - Social distress, aggravation, and impaired family circumstances. } \\
\text { - Parents cannot take up employment in SHIFT and LIFT because of lack of affordable } \\
\text { onsite childcare facilities }\end{array}$ & $\begin{array}{l}\text { SCI, SFC } \\
E P, V C, S C I \\
E P, V C \\
E P, S C I, V C \\
E P, S G, V C \\
V C, L C \\
\text { SCI, SFC } \\
\text { EP } \\
\text { EP } \\
\text { EP } \\
\text { SFC, VC } \\
\text { EP, VC } \\
\text { SG, VC } \\
\text { SCI, VC }\end{array}$ \\
\hline
\end{tabular}

likely to arise unless the project regeneration potentials are used efficiently and accordingly directed to prevent their occurrences or the circumstance by which they arise.

\section{Assessor's perspectives}

This HIA reinforces the assessor's views that it was important to engage and listen to local communities in any attempt to identify and evaluate the nature of concerns and impacts on their lives. The study provides confirmation that community perspectives on healthcare and regeneration potentials can be very different from those of professionals. The HIA found that Salford's high unemployment, relatively high crime levels, low incomes, poor attainment and achievement levels, and poor occupational progression created a feeling of low esteem and dependency in many of its communities. Yet the locals, independently and in their community groups, were aware of their situations and of the nature of the regenerational inputs from the project, and the local authority, that would help to improve their situations. The resultant view is that the locals should be trusted and the "bottoms up" approach encouraged in HIA assessment.

Throughout the course of the assessment, local people have raised issues that sprang from different perspectives and understanding of the role of the PCT health and social centres in the communities. Although the assessor's remit was to carry out the HIA in relation to development effects of the SRHT site and the PCT centres together, it became clear during the assessments that there was a need for a separate and thorough appraisal of the primary care centres. That was, with regard to their location, the potential health impacts of each on the communities in particular areas of Salford, the nature of the intended services, their role as centres of social and community activities, and their potential for providing local employment.

\section{Steering group perspectives}

Steering group member 1 -director of public health of Salford

It was reasoned and accepted that a HIA exercise would highlight the potential to link the SHIFT project to the regeneration of Salford. As the assessment progressed, it became apparent that the study was carrying out part of the consultative process by introducing the SHIFT project to communities in Salford who were unaware of such a major proposal to redesign health and social care in Salford. The HIA therefore introduced a level of community involvement in SHIFT that had previously been missing.

The HIA did not so much introduce new ideas about the wider determinants of population health as highlighted the key factors and brought them to the recognition of the Partnership Board. The full report, with its extensive impact tables, linked the expression of these determinants to specific, current, and major proposals for investment in Salford. ${ }^{2}$ The HIA was successful in capturing the preference of Salford communities for investments that would affect their general wellbeing rather than solely the provision of better health care. The HIA made more tangible the potential links between the SHIFT project and existing projects to develop the Salford economy through employment and training opportunities. It made a significant step forward by presenting the findings in a format that mirrored the Salford community plan. This placed the SHIFT proposal in the middle of the local strategic planning process. The HIA of the SHIFT project was successful in meeting its aim of recommending changes to the project to maximise the positive health impacts of the developments. However, it remains to be seen whether such recommendations can withstand the highly pressured environment of the modernisation of the NHS.

\section{Steering group member 2-chief officer of Salford Community Health Council}

The SHIFT project is the most important NHS development in Salford and as the HIA has shown will be a major factor in the long term development of the city and the quality of life of its citizens. From the start Salford CHC lobbied strongly for an assessment of the scheme's economic, social, environmental, and health impact on Salford. Given the scale of the proposals, Salford CHC saw their collective potential to have a major effect on quality of life in the city. Salford PCT agreed 
Table 3 Summary of health impacts in the social and economic category of health determinants

\section{Category of influence}

Social, cultural and economic, enterprise and business links, community participation, peer pressure

\section{Positive impacts}

- Direct employment during both phases of economic regeneration potentials

- Provided a range of employment across Salford's communities

- Benefits of business and supply links with the local Salford economy

- Increased community activities through community cafes bring people of all ages together.

- The project attracts inward investments and enhances the attractiveness of Salford and the city is seen as a good place for a career by professional

- Enhanced culture and prestige through a reduction in social exclusion, stress through education leading to improved job opportunities.

- Enhanced life chances of disadvantaged community groups

- Peer pressure reduced due to active involvement with the project and as quality of life improves, youth crime and antisocial behaviour are reduced.

- Uplift, feelings of esteem, and increased pride in the communities as local people take up professional careers with SHIFT and LIFT.

- Social networks improve to enhance the opportunities for community inclusion

- Business links provide the opportunity to develop community enterprises and social businesses.

- The local economy develops as SHIFT and LIFT use and help to develop local supply chains.

- Opportunity to develop networks and community participation.

- Addressed inequalities and promote inclusion of Salford's community groups and peoples

Negative impacts

- Decreased trade for local shops and businesses during the development phase that do not recover during the operational phase.

- Low entrepreneurial esteem and increased dependency as local business and supply links are not realised.

- Without necessary education and training the gap between the skills available and those required in both the NHS and the commercial sector in Salford continue to widen.

- Anger, frustration, and resentment from the disruption to communities creates social isolation.

- Reinforced feeling of low self esteem and psychological wellbeing because of lack of engagement between SHIFT and LIFT and local communities.

- Social exclusion of minority groups.

- Lip service paid and the services promised by the project are not realised.

- Lack of facilities from the project encourages unsocial behaviour.

- Community members are frightened of reporting crime.

- An unsympathetic Trust leads to frustration in the communities.

- The project does not involve communities in crime prevention.

- Breakdown in social interaction around the centres as families do not visit because of poor access.

- Local people continue to feel that they do not get feedback from consultations.

- No access to GPs in the evening after work.
Community plan theme groups linked to each impact

EP

$\mathrm{EP}, \mathrm{SCl}$

EP

SCl, SFC, LC

SG

$\mathrm{SCl}, \mathrm{VC}$

$\mathrm{SCl}$

SC, SFC

SFC, EP

$\mathrm{SFC}, \mathrm{SCl}$

EP

EP, SFC

SFC

$\mathrm{SCl}, \mathrm{VC}$

EP

EP

EP

$\mathrm{SCl}$

$E P, S G, S C l$

EP

EP, SG

SFC

SFC

SG

SFC

SFC, EP

SFC, SG

SG

Abbreviations as in table 1.

Table 4 Summary of health impacts in the physical environment categories of health determinants

\section{Category of influence}

Physical environment, buildings, urban form, wastes, public safety

\section{Positive impacts}

- The inward investments enhance the physical attractiveness of Salford

- New buildings design out crime.

- Local healthcare facilities in Salford's outer districts.

- Better housing resulting from job creation and influx of money in the city and generated by the joint project.

Negative impacts

- Environmental impacts, such as air quality, and noise during clearance and development affect health.

- Anxiety, stress, and frustration because of increase in traffic.

- Light pollution from healthcare buildings increases

- Increase air pollution from generated traffic at the main SRHT site and at the new local centres leads to the adverse effect on the respiratory health of loca residents.

- Increase in road safety problems and accidents.

- Drop in house prices near the development and reduced access to homes lead to stress.

- Reduction of healthcare facility during construction.

- Visual intrusion, security, and safety issues.

- Danger to health because of open site, untidy, collects rubbish, and fly tipping

- Accidents and risk behaviour from children and youths using the sites during the development phase.

- The health sector's continued extensive car dependent workforce from outside Salford continues.

- Continued parking problems around SRHT and the new centres.
Community plan theme groups linked to each impact

EP

$\mathrm{SCl}, \mathrm{VC}$

$\mathrm{SCl}, \mathrm{EP}$

SG, SCl

$E P, S G, S C l$

SG

$\mathrm{EP}, \mathrm{SG}, \mathrm{SCl}, \mathrm{VC}$

SFC, SG, SCl, VC EP

SFC, SCl

SFC, SG

SFC, SG, VC

SFC, SG, VC

SG, SCI

SFC, SG, SCl, VC

Abbreviations as in table 1. 
Table 5 Summary of health impacts in the public service category of health determinants

\begin{tabular}{lll}
\hline Category of influence & Positive impacts & Community plan theme groups \\
linked to each impact
\end{tabular}

to ensure that the SHIFT partners implement the recommendations of the HIA and exploit the opportunities to maximise investment opportunities for local firms in Salford when establishing contracts with the preferred private sector partners. The HIA suggested that the SHIFT partners should work with the Salford Partnership to exploit opportunities in education, commerce, and employment and seek to link with social care led initiatives wherever possible.

It was particularly significant that the HIA actively sought the views of a range of local citizens, as well as influential professionals, as this gave the findings and recommendations more reality and force. The HIA made it clear that nonclinical related issues arising or linked to the SHIFT and LIFT projects need to be considered. The study also highlighted the relevance of many non-NHS agencies to health status in the city. The recognition by the NHS agencies in particular of their impact (other than through healthcare delivery) on the quality of life in the city has been significantly heightened. In parallel, it has helped other agencies to recognise the contribution that the NHS might make to their own fields of endeavour.

\section{Steering group member 3-neighbourhood coordinator, Salford City Council}

The HIA findings have many implications for the project and for all members of the Salford Partnership. The HIA makes explicit the need for the Trust to reassess its relationship with the wider community and its impacts, both positive and negative, on Salford. In particular, the Trust and other partners should identify employment opportunities created by SHIFT and LIFT and develop training to help local people access those opportunities. This applies to both the project's construction and operational phases. Local supply chains should be used wherever practicable throughout SHIFT. This

Table 6 Summary of health impacts in the public policy category of health determinants

\begin{tabular}{|c|c|c|}
\hline Category of influence & Positive impacts & $\begin{array}{l}\text { Community plan theme groups } \\
\text { linked to each impact }\end{array}$ \\
\hline $\begin{array}{l}\text { Public policy, national and local } \\
\text { priorities }\end{array}$ & $\begin{array}{l}\text { - Commitment for each local centre to work directly with nurseries and } \\
\text { schools around health promotion. } \\
\text { - Improvement in mental health and wellbeing for Salford's communities by } \\
\text { looking at different ways to improve health outside medical facilities } \\
\text { - Improved health and wellbeing because of holistic approach based around } \\
\text { policy of consultation and partnership. } \\
\text { Negative impacts } \\
\text { - Community disillusionment if national targets override local priorities that } \\
\text { reduce the potentials to enhance local wellbeing. } \\
\text { - Expected health gains are unrealised because of power struggle between the } \\
\text { Trusts and the communities. } \\
\text { - Priorities and conflicts in SHIFT and LIFT budgets result in unrealised health gains. } \\
\text { - SHIFT and LIFT are not accountable to local people. }\end{array}$ & $\begin{array}{l}\text { VC, LC } \\
\text { SG, SCI } \\
\text { EP, SCI, VC } \\
\text { SFC } \\
\text { SFC } \\
\text { SG, SCI }\end{array}$ \\
\hline
\end{tabular}


objective should perhaps be strongly pursued through the Salford Partnership so that other partners also develop this objective. This suggests that SRHT should be represented on the Salford Partnership. At the time of writing, Salford PCT represents the whole of the local NHS on the Partnership.

The HIA study suggests that the wider NHS needs to radically rethink its role as a partner in increasing the wellbeing of citizens. This includes rethinking the range of uses its buildings can accommodate, for example, youth and community activities. It further suggests that the NHS needs to radically rethink its role as a neighbour, and as part of a community, and how it interfaces physically and socially with locals and environment. As the HIA suggests, the NHS and other partners need to minimise the impact of road traffic upon the city and its communities. It needs to build on the participation and communication initiatives that have been a part of SHIFT.

\section{CONCLUSIONS}

This research conducted a health impact assessment of the combined SHIFT and LIFT project. The assessment was wide ranging in its considerations by eliciting the views of experts, community groups across the city and by carrying out a comprehensive HIA. The study found that the perception of health across communities of Salford was much wider than that which was based upon medical or clinical perspectives. Salford people reported a view that was based upon the philosophy of healthy living and wellbeing. It is in these respects that the assessor recommended the need for the SHIFT and LIFT Partnership to extend their operational definitions of health, from the traditional clinical service provisions and delivery perceptions, to include considerations for social inclusion and activities by which to improve wellbeing and healthy living for the communities across culture, ethnicity, and gender in Salford. More consultation by the Trusts and SHIFT Partnership and greater community involvement was a recurring theme throughout the assessment process. They should provide support for vulnerable individuals, and support parents and families in the city.

\section{ACKNOWLEDGEMENTS}

We thank the experts and local people who took part in this research. We also thank the Capital Development Directorate of Salford Royal Hospital NHS Trust for their support and funding of the HIA.

\section{Authors' affiliations}

C H Douglas, School of Environment and Life Sciences, University of Salford, UK

A Higgins, Oldham PCT, UK

C Dabbs, CHC, Salford, UK

M Walbank, Salford City Council, UK

Funding: the Capital Development Directorate of Salford Royal Hospital NHS Trust.

Conflicts of interest: none declared.

\section{REFERENCES}

1 Department of Health. Saving lives: our healthier nation. London: HMSO, 1999.

2 Douglas CH. Health impact assessment of the SHIFT project. Salford: School of Environment and Life Sciences, University of Salford, 2002.

3 The NHS Plan. A plan for investment and reform, Presented to Parliament by the Secretary of Health by Command of Her Majesty, Cm4818-I. London: HMSO, 2000.

4 Scott-Samuel A, Birley M, Ardern A. The Merseyside guidelines for health impact assessment. 2nd edn. Liverpool: Merseyside Health Impact Assessment Steering Group, 2001.

5 Birley $M$. A review of trends in health impact assessment and the nature of the evidence used. Environmental Management and Health 2002;13, 1:21-39.

6 McCarthy M, Biddulph JP, Utley M, et al. A health impact assessment model for environmental changes attributable to development project. J Epidemiol Community Health 2002;56:611-16.

7 Douglas M, Scott-Samuel A. Addressing health inequalities in health impact. J Epidemiol Community Health 2001;55:450-1.

8 Naidoo J, Wills J, eds. Health studies: an introduction. Basingstoke: Palgrave, 2001.

9 Scott-Samuel A. Health impact assessment-theory into practice. J Epidemiol Community Health 1998;52:704-5.

10 Abdel-Aziz MI, Radford J, McCabe J. Health impact assessment, Finningley Airport. Doncaster: Doncaster Health Authority, Sep 2000.

11 Fleeman N Jeffrey V. A health impact assessment of a proposed sports centre in Parr. Observatory Report Series. Liverpool: Liverpool Public Health Observatory, 2000:49.

12 Salford City Council. City of Salford Community Plan. Swinton, Salford: Salford City Council, 2001.

13 Salford City Council. Area Regeneration Task Group report, interim report Salford: Salford City Council, 2001. 